\title{
Effectiveness of intravenous immunoglobulin for children with severe COVID-19: a rapid review
}

\author{
Jingyi Zhang, ${ }^{1,2 \#}$, Yinmei Yang ${ }^{3,4,5 \#}$, Nan Yang ${ }^{2 \#}$, Yanfang $\mathrm{Ma}^{2}$, Qi Zhou ${ }^{6}$, Weiguo $\mathrm{Li}^{3,4,5}$, Xia Wang ${ }^{3,4,5}$, \\ Liping Huang ${ }^{3,4,5}$, Xufei Luo ${ }^{1,2}$, Toshio Fukuoka ${ }^{7,8}$, Hyeong Sik Ahn,10, Myeong Soo Lee ${ }^{11,12}$, Zhengxiu Luo ${ }^{3,4,5}$, \\ Yaolong Chen ${ }^{1,2,13,14,15}$, Enmei Liu ${ }^{3,4,5}$, Kehu Yang ${ }^{1,2,15}$, Zhou Fu ${ }^{3,4,5}$, on behalf of COVID-19 Evidence and \\ Recommendations Working Group
}

${ }^{1}$ School of Public Health, Lanzhou University, Lanzhou 730000, China; ${ }^{2}$ Evidence-based Medicine Center, School of Basic Medical Sciences, Lanzhou University, Lanzhou 730000, China; ${ }^{3}$ Department of Respiratory Medicine, Children's Hospital of Chongqing Medical University, Chongqing 400014, China; ${ }^{4}$ National Clinical Research Center for Child Health and Disorders, Ministry of Education Key Laboratory of Child Development and Disorders, China International Science and Technology Cooperation Base of Child Development and Critical Disorders, Children's Hospital of Chongqing Medical University, Chongqing 400014, China; ${ }^{5}$ Chongqing Key Laboratory of Pediatrics, Chongqing 400014, China; ${ }^{6}$ The First School of Clinical Medicine, Lanzhou University, Lanzhou 730000, China; ${ }^{7}$ Emergency and Critical Care Center, the Department of General Medicine, Department of Research and Medical Education at Kurashiki Central Hospital, Okayama, Japan; ${ }^{8}$ Advisory Committee in Cochrane Japan, Tokyo, Japan; ${ }^{9}$ Department of Preventive Medicine, Korea University College of Medicine, Seoul, Korea; ${ }^{10}$ Korea Cochrane Centre, Seoul, Korea; ${ }^{11}$ Korea Institute of Oriental Medicine, Daejeon, Korea; ${ }^{12}$ University of Science and Technology, Daejeon, Korea; ${ }^{13}$ Lanzhou University, an Affiliate of the Cochrane China Network, Lanzhou 730000, China; ${ }^{14}$ Chinese GRADE Center, Lanzhou 730000 , China; ${ }^{15}$ Key Laboratory of Evidence Based Medicine and Knowledge Translation of Gansu Province, Lanzhou University, Lanzhou 730000, China

Contributions: (I) Conception and design: Y Chen, E Liu; (II) Administrative support: K Yang, Z Fu; (III) Provision of study materials or patients: J Zhang, Y Yang; (IV) Collection and assembly of data: Y Yang, N Yang; (V) Data analysis and interpretation: Y Ma, J Zhang; (VI) Manuscript writing: All authors; (VII) Final approval of manuscript: All authors.

\#These authors contributed equally to this work.

Correspondence to: Zhou Fu. Department of Respiratory Medicine, Children's Hospital of Chongqing Medical University, Chongqing 400014, China. Email: fu_zhou79@aliyun.com; Kehu Yang. School of Public Health, Lanzhou University, Lanzhou 730000, China. Email: kehuyangebm2006@126.com.

Background: Intravenous immunoglobulin (IVIG) is usually used as supportive therapy, but the treatment of COVID-19 by IVIG is controversial. This rapid review aims to explore the clinical effectiveness and safety of IVIG in the treatment of children with severe COVID-19.

Methods: We systematically searched the literature on the use of IVIG in patients with COVID-19, severe acute respiratory syndrome (SARS) or Middle East respiratory syndrome (MERS), including both adults and children. We assessed the risk of bias and quality of evidence and reported the main findings descriptively.

Results: A total of 1,519 articles were identified by initial literature search, and finally six studies met our inclusion criteria, included one randomized controlled trial (RCT), four case series and one case report involving 198 patients. One case series showed the survival of COVID-19 patients with acute respiratory distress syndrome (ARDS) was not improved by IVIG. One case report showed high-dose IVIG could improve the outcome of COVID-19 adults. Three observational studies showed inconsistent results of the effect of IVIG on SARS patients. One RCT showed that IVIG did not reduce mortality or the incidence of nosocomial infection in adults with severe SARS. The quality of evidence was between low and very low.

Conclusions: The existing evidence is insufficient to support the efficacy or safety of IVIG in the treatment of COVID-19.

Keywords: COVID-19; children; intravenous immunoglobulin (IVIG); rapid review

Submitted Apr 14, 2020. Accepted for publication Apr 26, 2020.

doi: 10.21037/atm-20-3305

View this article at: http://dx.doi.org/10.21037/atm-20-3305 


\section{Introduction}

COVID-19 is an infectious disease caused by severe acute respiratory syndrome coronavirus 2 (SARS-CoV-2) (1). SARS-CoV-2 belongs to the family of coronaviruses, which are enveloped viruses that can cause illnesses ranging from common cold to severe diseases such as SARS and MERS $(2,3)$. The COVID-19 epidemic massively influences the public health and people's daily lives, and the disease was declared a pandemic on 11 March 2020 (4). All populations are susceptible to infection and there is a research shows children are as likely to be infected as adults (5). On February 11, 2020, there were 44,672 confirmed cases in mainland China, of whom 416 were under the age of 10 years and 549 between the ages of 10 to 19 years (6). The main symptoms in children are fever and cough, and the disease is on average less severe in children than adults (7). However, severe cases have been reported also in children (8). So far, there has been no specific treatment for COVID-19, antiviral therapy and vaccination are currently under development $(9,10)$.

IVIG is prepared from the plasma of healthy humans and usually used as supportive therapy. Its main component is immunoglobulin (Ig) G, which has dual therapeutic effects of immune-modulation effects and immune substitution (11). IVIG is one of the alternative treatments for children with agammaglobulinemia, and an effective treatment of Kawasaki disease $(12,13)$. IVIG was used to treat SARS patients during the SARS outbreak in $2003(14,15)$, but there is no convincing evidence of its effectiveness. According to recent reports, about $33 \%$ of patients with severe COVID-19 received IVIG in China (16). Some published guidelines of COVID-19 have indicated that IVIG could be used to treat children with severe or critical disease (17).

The purpose of this study is to perform a comprehensive rapid review to explore whether it is beneficial to treat children with severe COVID-19 with IVIG and provide supporting evidence support for COVID-19 guidelines. Because of the urgent situation, the review was not registered (18). We present the following article in accordance with the PRISMA reporting checklist (available at http://dx.doi.org/10.21037/atm-20-3305).

\section{Methods}

\section{Search strategy}

We carried out a comprehensive search in the following electronic databases: the Cochrane library, MEDLINE (via PubMed), EMBASE, Web of Science, China Biology Medicine disc (CBM), China National Knowledge Infrastructure (CNKI), and Wanfang Data, by using the terms "COVID-19", "SARS-CoV-2", "Novel coronavirus", "2019-novel coronavirus", "2019-nCoV", "SARS", "MERS", "IVIG", "intravenous immunoglobulin" and their derivatives. The search covered the time from each database's inception to March 31, 2020. The search strategies were determined by multiple pre-searches and were discussed with the clinicians about the appellation of disease and IVIG. We also searched the World Health Organization Clinical Trials Registry Platform, ISRCTN Registry, ClinicalTrials, Google Scholar, three preprint services, including medRxiv (https://www.medrxiv.org/), bioRxiv (https://www.biorxiv.org/) and SSRN (https://www. ssrn.com/index.cfm/en/) and references of included studies. The details of the search strategy can be found in the supplementary material.

\section{Inclusion and exclusion criteria}

We included RCTs that compared IVIG treatment (standard intravenous immunoglobulin (IVIG) preparations, excluding IgM-enriched Ig, hyperimmune Ig and specific Ig from convalescent plasma) with a control group (placebo or no treatment with IVIG), and cohort studies, crosssectional studies, case-control studies, case series and cases report that can distinguish the corresponding outcomes caused by IVIG. The inclusion of COVID-19 adult patients and patients with SARS or MERS helps to provide indirect evidence, if studies on COVID-19 in children are scarce. Studies with all patients diagnosed with COVID-19, SARS or MERS were included, without restrictions on age, race, gender, or geographical location or setting. The primary outcomes were the risk of death and survival probability. Secondary outcomes included the incidence of nosocomial infection, the duration of fever, time of the lung lesions subsided obviously, the progression of disease cascade, improvement in abnormal laboratory inspection indicators (total peripheral blood WBC, platelet counts, serum globulin, WBC counts), and adverse effects. We excluded duplicates, conference abstracts, comments and letters, studies published in languages other than English or Chinese, and studies where we could not access the full text.

\section{Study selection}

After eliminating duplicates by EndNote software and 
manual check, two reviewers (J Zhang and Y Yang) independently reviewed the titles and abstracts of records retrieved from the search and selected all potentially relevant studies according to the pre-defined inclusion and exclusion criteria. After this, the same reviewers screened the full texts and made the final selection. A pilot search was conducted before the full screening of the literature to ensure that each researcher understood the screening criteria and process. Disagreements about selection of studies were resolved by consulting a third reviewer ( $\mathrm{N}$ Yang). The process of study selection was documented using a PRISMA flow diagram (19).

\section{Data extraction}

Two reviewers (J Zhang and Y Yang) independently extracted the following data from included trials using a standardized extraction sheet: (I) basic information (year of publication, first author and affiliation, journal, funding, conflict of interest); (II) study details (type of study, sample size, research purpose, research population characteristics, interventions; and (III) outcome data. A pre-test was conducted before formal extraction to ensure that each researcher agreed with the extraction criteria and process. Disagreements were solved through discussion with a third reviewer (N Yang).

\section{Risk of bias assessment}

Two reviewers (J Zhang and Y Ma) assessed the quality of the included studies independently. We used the Cochrane bias risk assessment tool (Risk of bias) to assess RCTs (20), the criteria recommended by the National Institute of Health and Clinical Optimization (NICE) for case series to assess the risk of bias (21), the Joanna Briggs Institute'(JBI) case report quality appraisal tool for case reports(22) Newcastle-Ottawa Quality Assessment Scale (NOS) for the quality of cohort studies and case-control studies (23), and Agency for Healthcare Research and Quality (AHRQ) tool for cross-sectional studies (24).

\section{Data synthesis}

If the data were enough to be summarized, we would conduct a meta-analysis using Review Manager 5.3. For dichotomous outcomes we calculated the risk ratio (RR) and the corresponding $95 \%$ confidence interval (CI) and
$\mathrm{P}$ value. For continuous outcomes, we calculated the mean difference (MD) and its corresponding 95\% CI when means and standard deviations (SD) were reported. If sufficient data were available, we considered examined the robustness of meta-analyses in a sensitivity analysis. When effect sizes could not be pooled, we reported the study effectives narratively.

\section{Quality of the evidence assessment}

The quality of the body of evidence was graded using the GRADE method $(25,26)$. Evidence from randomized trials could be downgraded by the following five factors: risk of bias, inconsistency of results, indirectness of evidence, imprecision of results, and publication bias (Table S1). The quality of evidence for each outcome was graded as high, medium, low, or very low. The results of the grading were presented in "GRADE evidence profile" (27-30).

\section{Results}

We identified 1,519 articles in the initial literature search (Figure 1). After removing duplicates, we screened the titles and abstracts of 1,405 records. Thirty-one articles were retrieved for full-text reviewing. Finally, one RCT, four case series and one case report involving a total of 198 patients were included for rapid review (31-36).

The studies were published between 2003 and 2020, and all studies were from China (Table 1). We found one case series on IVIG in COVID-19 adults with acute respiratory distress syndrome (ARDS), one case report in COVID-19 adults, one RCT of 44 adults with severe SARS, which included 25 adults with acute lung injury (ALI) and 19 adults with ARDS, one case series involving children with SARS, and two case series also involving adults with SARS. In all studies IVIG was used before or in combination with other drugs and treatment (such as antibiotics, glucocorticoids, antivirals, oxygen therapy). The IVIG dose and duration of use differed across studies.

\section{Risk of bias for included studies}

We found a high risk of bias in random sequencing, allocation concealment and blinding in the only included RCT. All case series had a moderate risk (score 4 to 5 out of 8) (Table 1), one case report meeting 8 of the 8 items of the JBI quality appraisal tool. 


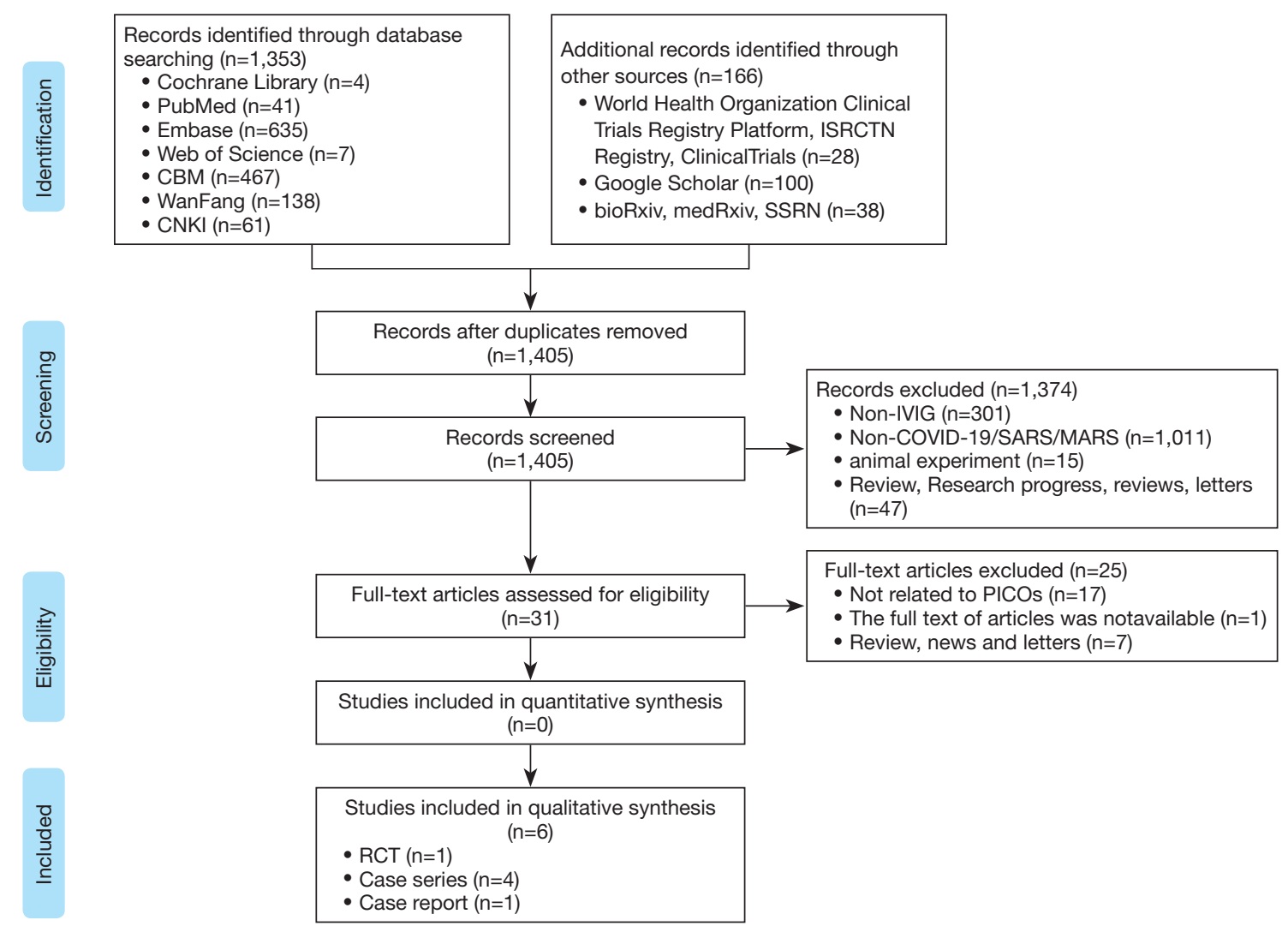

Figure 1 The flow chart of the literature search.

Table 1 Basic characteristics of the included studies

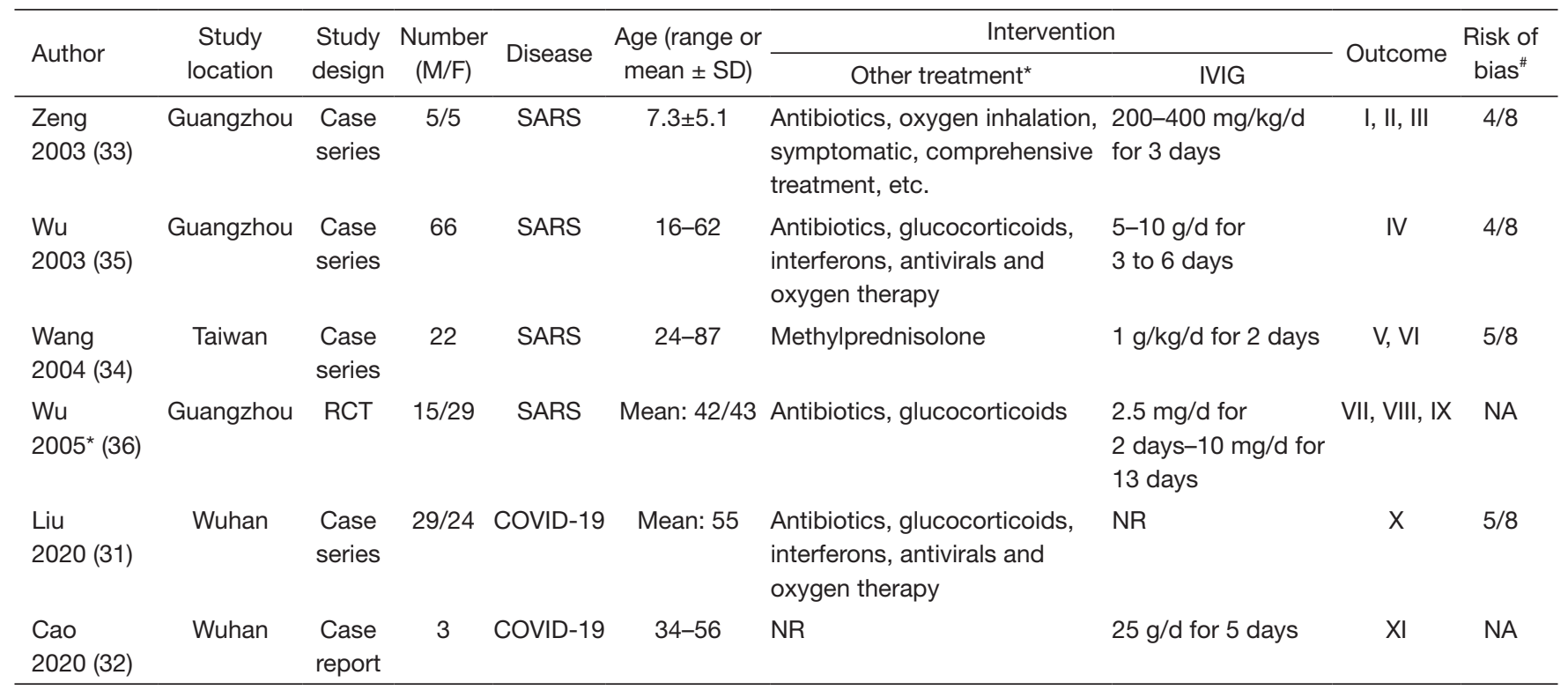

Outcome: I: the duration of fever; II: total peripheral blood WBC $\left(10^{9} / \mathrm{L}\right)$; III: time of the lung lesions subsided obviously; IV: adverse effects; V: WBC counts $\left(10^{9} / \mathrm{L}\right)$; VI: platelet counts $\left(10^{9} / \mathrm{L}\right)$; VII: serum globulin $(\mathrm{g} / \mathrm{L})$; VIII: the incidence of nosocomial infection; IX: the risk of death; X: survival probability; XI: the progression of disease cascade. *, prior to IVIG treatment, the patient received other treatment; ${ }^{\text {, }}$, risk of bias in case series. NR, not report; NA, not applicable. 


\section{Quality of the evidence}

The quality of evidence for all outcomes assessed in the only included RCT was graded low (Table S2), primarily due to serious risk of bias and imprecision. As we included four case series, we judged that reporting a 'GRADE evidence profile' would not be meaningful. Overall, the quality of evidence was very low for most outcomes and cannot thus provide a reliable indication of any likely effect across outcomes.

\section{COVID-19}

A case series of 109 adults with COVID-19 reported that most patients used antibiotics and antiviral treatment, and over half of the patients were given glucocorticoid therapy and IVIG. The survival probability of patients with ARDS could not be improved by antiviral, glucocorticoid, or Ig treatment. The risk of death was not associated with the use of IVIG in the patients with ARDS (31). A case report of three adults with COVID-19 reported that a high dose IVIG ( $25 \mathrm{~g} / \mathrm{d}$ for 5 days) administered at the appropriate point could successfully block the progression of disease cascade (result of the clinical symptoms, laboratory inspection indicators and chest CT scan), and finally improve the outcome of COVID 19 (32).

\section{SARS}

The incidence of nosocomial infection and the risk of death

The RCT of 44 adults with severe SARS found no significant difference in the risk of death $(18.1 \% \mathrm{vs}$. $23.8 \%)$ or the incidence of nosocomial infection $(65.2 \%$ vs. $52.4 \%$ ) between adults treated either with IVIG or with conventional treatment. And there was no significant difference in the incidence of nosocomial infection between $\operatorname{ALI}(50.0 \%$ vs. $38.5 \%)$ and ARDS (81.8\% vs. $75.0 \%)$ patients (36).

\section{Laboratory inspection}

One case series reported the patients with SARS who did not receive steroids for severe hemocytopenia had increased WBC counts and platelet counts after undergoing IVIG (34). Another case series reported the children with persistent fever who were given IVIG had significantly improved total peripheral blood WBC after undergoing
IVIG (33). The included RCT showed the serum globulin increased slightly in the IVIG group, but decreased in the conventional treatment group and the difference was not significant (36).

\section{The duration of fever}

One case series included ten children with persistent fever who were given IVIG. The body temperature ranged between 38.4 and $40{ }^{\circ} \mathrm{C}$ at baseline and the duration of fever was 1 to 4 days after IVIG (33).

\section{Imaging testing}

One case series reported that chest radiographs in children who were given IVIG showed more patchy focal asymmetric infiltrative shadows, more rapid time of the lung lesions subsided obviously than in a randomly selected, age- and sexmatched control group of 20 children without IVIG (33).

\section{Adverse effects}

One case series reported no adverse effects associated with the use of IVIG in the early stage of the disease in patients with high fever and other symptoms, or for patients with WBC count below $3.0 \times 10^{9} / \mathrm{L}(35)$.

\section{Discussion}

We only found limited evidence about the use of IVIG to treat children or adults with severe COVID-19. Since SARS and COVID-19 belong to the same family of viruses, we used IVIG treatment of SARS as indirect evidence, even though the quality of the included studies was generally low. The results were also inconsistent, and no benefit was found in the only identified RCT.

An earlier systematic review of treatment effects with SARS concluded that although four studies suggested an improvement in the patients' condition after IVIG treatment, more controlled trials are needed to provide evidence of the potential benefits on IVIG against SARS. The results of the review are roughly in line with our findings, more high-quality evidence about the benefits and disadvantages of IVIG for COVID-19 and SARS are needed (37).

There was no apparent benefit from IVIG, despite it being used to treat other respiratory infections. A metaanalysis of seven RCTs in children aged less than three years with respiratory syncytial virus infection found no evidence of differences between children treated with IVIG or with 
placebo in the risk of death ( $\mathrm{RR}=0.87,95 \%$ CI: $0.14-5.27)$ or serious adverse events ( $\mathrm{RR}=1.08,95 \% \mathrm{CI}$ : 0.65-1.79), or in the duration of hospitalization ( $\mathrm{MD}=-0.70,95 \%$ CI: -1.83 to 0.42 ) (38). SARS belongs to the category of systemic inflammatory response syndromes (SIRS), and severe SARS often manifests as ALI, ARDS and progresses to severe sepsis $(39,40)$. The course of COVID-19 may also be similar. A meta-analysis of nine RCTs showed that IVIG did not reduce the mortality (OR $=0.95,95 \%$ CI: $0.80-1.13$ ), length of hospital stay $(\mathrm{MD}=-4.08,95 \% \mathrm{CI}:-6.47$ to -1.69 ), or the risk of death or major disability before two years of age ( $R R=0.98,95 \%$ CI: $0.88-1.09)$ in infants with suspected or confirmed infection, compared with placebo or no intervention (41).

IVIG is prepared from pools of plasma obtained from several thousand healthy blood donors. Unlike convalescent plasma from patients with COVID-19, IVIG does not contain SARS-Cov-2 neutralizing antibody $(42,43)$. The review showed that there was no evidence that IVIG has an effect on anti-MERS-CoV, or that IVIG would cause kidney failure or thrombosis in patients with MERS (44). IVIG could increase the risk of vaccination delay. A study by National Advisory Committee on Immunization and the American Advisory Committee on Immunization showed a delay of five months of varicella vaccine in patients who received IVIG and varicella immune globulin (VZIG) (45). IVIG may increase the risk of infections transmitted by transfusion (42). Some adverse effects, such as thrombosis, aseptic meningitis, hemolysis, and renal failure, are mainly associated with the use of high-dose IVIG (46).

The condition, dose and duration of IVIG were inconsistent between studies, the efficacy, and the associated adverse effects remain unclear. The first severe case of COVID-19 in children in China took IVIG with a dose of $400 \mathrm{mg} / \mathrm{kg}$ for a duration of five days (8). The recommended dosage of IVIG for children with severe COVID-19 was also inconsistent in different guidelines, including $1.0 \mathrm{~g} / \mathrm{kg} / \mathrm{d}$ for 2 days, or $400 \mathrm{mg} / \mathrm{kg} / \mathrm{d}$ for 5 days, $0.2 \mathrm{~g} / \mathrm{kg} / \mathrm{d}$ for $3-5$ days, or $1-2 \mathrm{~g} / \mathrm{kg}$ for $2-3$ days (47-49).

Therefore, it is particularly important and urgent to study the benefits and disadvantages of IVIG treatment in children with COVID-19. It is promising that a trial addressing efficacy and safety of IVIG therapy in patients with severe or critical COVID-19 disease has been registered on (50). Randomized, double-blinded, large sample, multicenter clinical trials on children are urgently needed for getting scientific evidence to support clinical decision-making.

\section{Strength and limitations}

This is the first rapid review of IVIG treatment for children with COVID-19. There are several limitations in this systematic review. First, the use of glucocorticoids or a combination of a variety of broad-spectrum antibiotics before IVIG may lead to changes in the microecology of the body, affect the immune regulation function, and thus also affect the effect of IVIG. Second, the total sample size of this study was insufficient to make strong conclusions, and the quality of the methodology was generally low which affect the certainty of the results. Finally, we may have missed some studies as we only included studies published in Chinese and English.

\section{Conclusions}

There is no direct evidence for IVIG in children with COVID-19, current evidence is insufficient to assess the effectiveness and safety of IVIG for children with severe COVID-19. Therefore, we cannot suggest use of IVIG for the treatment of COVID-19 in children. More clinical studies to address this topic are needed.

\section{Acknowledgments}

We thank Janne Estill, Institute of Global Health of University of Geneva for providing guidance and comments for our review. We thank all the authors for their wonderful collaboration.

Funding: This work was supported by grants from National Clinical Research Center for Child Health and Disorders (Children's Hospital of Chongqing Medical University, Chongqing, China) (grant number NCRCCHD-2020EP-01); Special Fund for Key Research and Development Projects in Gansu Province in 2020; The fourth batch of "Special Project of Science and Technology for Emergency Response to COVID-19" of Chongqing Science and Technology Bureau. Special funding for prevention and control of emergency of COVID-19 from Key Laboratory of Evidence Based Medicine and Knowledge Translation of Gansu Province (grant number No. GSEBMKT2020YJ01); The Fundamental Research Funds for the 
Central Universities (lzujbky-2020-sp14).

\section{Footnote}

Reporting Checklist: The authors have completed the PRISMA reporting checklist. Available at http://dx.doi. org/10.21037/atm-20-3305

Conflicts of Interest: All authors have completed the ICMJE uniform disclosure form (available at http://dx.doi. org/10.21037/atm-20-3305). MSL serves as the unpaid editorial board member of Annals of Translational Medicine from Nov 2019 to Oct 2021. The other authors have no conflicts of interest to declare.

Ethical Statement: The authors are accountable for all aspects of the work in ensuring that questions related to the accuracy or integrity of any part of the work are appropriately investigated and resolved.

Open Access Statement: This is an Open Access article distributed in accordance with the Creative Commons Attribution-NonCommercial-NoDerivs 4.0 International License (CC BY-NC-ND 4.0), which permits the noncommercial replication and distribution of the article with the strict proviso that no changes or edits are made and the original work is properly cited (including links to both the formal publication through the relevant DOI and the license). See: https://creativecommons.org/licenses/by-nc-nd/4.0/.

\section{References}

1. Zhu N, Zhang D, Wang W, et al. A novel coronavirus from patients with pneumonia in China, 2019. N Engl J Med 2020;382:727-33.

2. Chan JFW, Kok KH, Zhu Z, et al. Genomic characterization of the 2019 novel human-pathogenic coronavirus isolated from a patient with atypical pneumonia after visiting Wuhan. Emerg Microbes Infect 2020;9:221-36.

3. Lu R, Zhao X, Li J, et al. Genomic characterisation and epidemiology of 2019 novel coronavirus: implications for virus origins and receptor binding. Lancet 2020;395:565-74.

4. The World Health Organization, Coronavirus disease (COVID-19) Pandemic[Internet]. World Health Organization; c2020 [cited 2020 Apr 13]. Available online: https://www.who.int/emergencies/diseases/novelcoronavirus-2019
5. Bi Q, Wu Y, Mei S, et al. Epidemiology and Transmission of COVID-19 in Shenzhen China: Analysis of 391 cases and 1,286 of their close contacts. MedRxiv 2020 [cited 2020 Apr 13]. Available online: https://www.medrxiv.org/ content/10.1101/2020.03.03.20028423v3

6. Wu Z, McGoogan JM. Characteristics of and important lessons from the coronavirus disease 2019 (COVID-19) outbreak in China: summary of a report of 72314 cases From the Chinese Center for Disease Control and Prevention. JAMA 2020;323:1239-42.

7. Wang XF, Yuan J, Zheng Y, et al. Clinical and epidemiological characteristics of 34 children with 2019 novel coronavirus infection in Shenzhen. Zhonghua Er Ke Za Zhi 2020;58:E008.

8. Chen F, Liu Z, Zhang F, et al. The first case of children with severe novel coronavirus pneumonia in China. Chin J Pediatr 2020;58.

9. Lai CC, Shih TP, Ko WC, et al. Severe acute respiratory syndrome coronavirus 2 (SARS-CoV-2) and corona virus disease-2019 (COVID-19): the epidemic and the challenges. Int J Antimicrob Agents 2020:105924.

10. Han Q, Lin Q, Jin S, et al. Recent insights into 2019$\mathrm{nCoV}$ : a brief but comprehensive review. J Infect 2020;S0163-4453(20)30087-6.

11. Ferrara G, Zumla A, Maeurer M. Intravenous immunoglobulin (IVIg) for refractory and difficult-to-treat infections. Am J Med 2012;125:1036.e1-1036.e8.

12. Björkander J, Nikoskelainen J, Leibl H, et al. Prospective open-label study of pharmacokinetics, efficacy and safety of a new $10 \%$ liquid intravenous immunoglobulin in patients with hypo-or agammaglobulinemia. Vox Sanguinis 2006;90:286-93.

13. Crayne CB, Mitchell C, Beukelman T. Comparison of second-line therapy in IVIg-refractory Kawasaki disease: a systematic review. Pediatr Rheumatol Online J 2019;17:77.

14. Hui DSC. An overview on severe acute respiratory syndrome (SARS). Monaldi Arch Chest Dis 2005;63(3).

15. Zeng H. Diagnosis and treatment of severe acute respiratory syndrome in children. J Appl Clin Pediatr 2003;12:940-3.

16. Guan W, Ni Z, Hu Y, et al. Clinical characteristics of 2019 novel coronavirus infection in China. MedRxiv 2020 [cited 2020 Apr 13]. Available online: https://www.medrxiv.org/ content/10.1101/2020.02.06.20020974v1

17. National Health Commission of the People's Republic of China. Diagnosis and treatments of pneumonia infected by novel coronavirus (trial version 7). 2020. [cited $2020 \mathrm{Mar}$ 26]. Available online: http://www.nhc.gov.cn/yzygj/s7653p 
/202003/46c9294a7dfe4cef80dc7f5912eb1989.shtml

18. Ge L, Tian J, Li Y, et al. Association between prospective registration and overall reporting and methodological quality of systematic reviews: a meta epidemiological study. J Clin Epidemiol 2018;93:45-55.

19. Moher D, Liberati A, Tetzlaff J, et al. PRISMA Group. Preferred Reporting Items for Systematic Reviews and Meta-analyses: the PRISMA statement. BMJ 2009;339:b2535.

20. Higgins JPT, Thomas J, Chandler J, et al. Cochrane Handbook for Systematic Reviews of Interventions version 6.0 (updated July 2019). Cochrane, 2019. Available online: www.training.cochrane.org/handbook

21. National Institute for Health and Care Excellence 2003 [cited 2020 Mar 26]. Available online: https://www.nice. org.uk/guidance/cg3/documents/appendix-4-quality-ofcase-series-form2

22. The Joanna Briggs Institute. The Joanna Briggs Institute Reviewers' Manual 2016. Adelaide, SA Australia: The Joanna Briggs Institute, 2016.

23. Stang A. Critical evaluation of the Newcastle-Ottawa scale for the assessment of the quality of nonrandomized studies in meta analyses. Eur J Epidemiol 2010;25:603-5.

24. Nieva VF, Sorra J. Safety Culture Assessment: A Tool for Improving Patient Safety in Healthcare Organizations. Quality and Safety in Health Care 2003;12:ii17-23.

25. Norris SL, Meerpohl JJ, Akl EA, et al. The skills and experience of GRADE methodologists can be assessed with a simple tool. J Clin Epidemiol 2016;79:150-8.e1.

26. Guyatt GH, Oxman AD, Vist GE, et al. GRADE: an emerging consensus on rating quality of evidence and strength of recommendations. BMJ 2008;336:924-6.

27. Guyatt GH, Oxman AD, Montori V, et al. GRADE guidelines: 5 . Rating the quality of evidence-publication bias. J Clin Epidemiol 2011;64:1277-82.

28. Guyatt GH, Oxman AD, Kunz R, et al. GRADE guidelines 6. Rating the quality of evidence-imprecision. J Clin Epidemiol 2011;64;1283-93.

29. Guyatt GH, Oxman AD, Kunz R, et al. GRADE guidelines: 7. Rating the quality of evidenceinconsistency. J Clin Epidemiol 2011;64:1294-302.

30. Guyatt GH, Oxman AD, Kunz R, et al. GRADE guidelines: 8 . Rating the quality of evidence-indirectness. J Clin Epidemiol 2011;64:1303-10.

31. Liu Y, Sun W, Li J, et al. Clinical features and progression of acute respiratory distress syndrome in coronavirus disease 2019. MedRxiv 2020 [cited 2020 Apr 13]. Available online: https://www.medrxiv.org/content/10.1101/2020.02

\section{$.17 .20024166 v 3$}

32. Cao W, Liu X, Bai T, et al. High-dose intravenous immunoglobulin as a therapeutic option for deteriorating patients with Coronavirus Disease 2019. Open Forum Infect Dis 2020;7:ofaa102.

33. Zeng H, Liu L, Wang B, et al. Clinical analysis on treatment of severe acute respiratory syndrome in children with intravenous Immunoglobulin. J Clin Pediatr 2003;21:533-4, 585.

34. Wang JT, Sheng W, Fang C, et al. Clinical Manifestations, Laboratory Findings, and Treatment Outcomes of SARS Patients. Emerg Infect Dis 2004;10:818-24.

35. Wu W, Wang J, Liu P, et al. Clinical features of 96 patients with severe acute respiratory syndrome from a hospital outbreak. Zhonghua Nei Ke Za Zhi 2003;42:453-7.

36. Wu L, Xiao Z, Li Y. Intravenous Immunoglobulin was assisted treatment of 23 cases of severe infectious atypical pneumonia. J Jinan Univ (Natural Science \& Medicine Edition) 2005;26:826-8.

37. Stockman LJ, Bellamy R, Garner P. SARS: Systematic Review of Treatment Effects. PLoS Med 2006;3:e343.

38. Sanders SL, Agwan S, Hassan M, et al. Imunoglobulin treatment for hospitalised infants and young children with respiratory syncytial virus infection. Cochrane Database of Systematic Reviews 2019;8:CD009417.

39. Levy MM, Baylor MS, Bernard GR, et al. Clinical Issues and Research in Respiratory Failure from Severe Acute Respiratory Syndrome[J]. Am J Respir Crit Care Med 2005;171:518-26.

40. Booth CM, Stewart TE. Severe acute respiratory syndrome and critical care medicine: The Toronto experience. Crit Care Med 2005;33:S53-60.

41. Ohlsson A, Lacy JB. Intravenous immunoglobulin for suspected or proven infection in neonates. Cochrane Database of Systematic Reviews 2015;3:CD001239.

42. Desborough MJ, Miller J, Thorpe SJ, et al. Intravenous immunoglobulin-induced haemolysis: a case report and review of the literature. Transfus Med 2014;24:219-26.

43. Kazatchkine MD, Kaveri SV. Immunomodulation of autoimmune and inflammatory diseases with intravenous immune globulin. N Engl J Med 2001;345:747-55.

44. Mustafa S, Balkhy H, Gabere MN. Current treatment options and the role of peptides as potential therapeutic components for Middle East Respiratory Syndrome (MERS): A review. J Infect Public Health 2018;11:9-17.

45. Cabral D. A Guide to Contraindications to Childhood Vaccinations. Can J Infect Dis 2000;11:13-4.

46. Guo Y, Tian X, Wang X, et al. Adverse Effects of 
Immunoglobulin Therapy. Front Immunol 2018;9:1299.

47. Chen Z, Fu J, Shu Q, et al. Diagnosis and treatment recommendation for pediatric coronavirus disease-19. Zhejiang Da Xue Xue Bao Yi Xue Ban 2020;49:1-8.

48. Expert consensus on diagnosis and treatment of new coronavirus pneumonia in paediatrics of guangdong province. Guangdong Med 2020;41:217-21.

49. Chinese society of pediatrics. Recommendations for

Cite this article as: Zhang J, Yang Y, Yang N, Ma Y, Zhou Q, Li W, Wang X, Huang L, Luo X, Fukuoka T, Ahn HS, Lee MS, Luo Z, Chen Y, Liu E, Yang K, Fu Z, on behalf of COVID-19 Evidence and Recommendations Working Group. Effectiveness of intravenous immunoglobulin for children with severe COVID-19: a rapid review. Ann Transl Med 2020;8(10):625. doi: $10.21037 /$ atm-20-3305 diagnosis and prevention of 2019 novel coronavirus infection in children ( 1 edition). Chin J Pediatr 2020;58:169-74.

50. The Efficacy of Intravenous Immunoglobulin Therapy for Severe 2019-nCoV Infected Pneumonia[Internet]. c2020 [cited 2020 Apr 13]. Available online: Available online: https://clinicaltrials.gov/ct2/show/ NCT04261426? cond=2019-nCoV\&draw=2 


\section{Search strategy}

\section{EMBASE}

\#1 'middle east respiratory syndrome coronavirus'/exp

\#2 'severe acute respiratory syndrome'/exp

\#3 'sars coronavirus' / exp

\#4 'COVID-19':ab,ti

\#5 'SARS-COV-2':ab,ti

\#6 'novel coronavirus':ab,ti

\#7 '2019-novel coronavirus':ab,ti

\#8 'coronavirus disease-19':ab,ti

\#9 'coronavirus disease 2019':ab,ti

\#10 'COVID 19':ab,ti

\#11 'novel cov':ab,ti

\#12 '2019-ncov':ab,ti

\#13 '2019-cov':ab,ti

\#14 'middle east respiratory syndrome':ab,ti

\#15 'middle east respiratory syndrome coronavirus':ab,ti

\#16 'mers':ab,ti

\#17 'mers-cov':ab,ti

\#18 'severe acute respiratory syndrome':ab,ti

\#19 'sars':ab,ti

\#20 'sars-cov':ab,ti

\#21 'sars-related':ab,ti

\#22 'sars-associated':ab,ti

\#23 \#1-\#22/OR

\#24 'Immunoglobulins'/exp

\#25 'Intravenous Immunoglobulin*':ab,ti

\#26 'Intravenous IG':ab,ti

\#27 'immune globulin'”:ab,ti

\#28 'IVIG':ab,ti

\#29 'IV Immunoglobulin*':ab,ti

\#30 'Intravenous Antibodies':ab,ti

\#31 'gamma globulin'*':ab,ti

\#32 'gamma-globulin*':ab,ti

\#33 'Flebogamma DIF':ab,ti

\#34 'Gamunex':ab,ti

\#35 'Globulin-N':ab,ti

\#36 'Globulin N':ab,ti

\#37 'Intraglobin':ab,ti

\#38 'Gammagard':ab,ti

\#39 'Gamimune':ab,ti

\#40 'Gamimmune':ab,ti

\#41 'Privigen':ab,ti

\#42 'Sandoglobulin':ab,ti

\#43 'Venoglobulin':ab,ti

\#44 'Iveegam':ab,ti 


$\begin{array}{ll}\# 45 & \text { 'Endobulin':ab,ti } \\ \# 46 & \text { 'Gammonativ':ab,ti } \\ \# 47 & \text { \#24-\#46/OR } \\ \# 48 & \text { \#23 AND \#47 }\end{array}$

\section{PubMed}

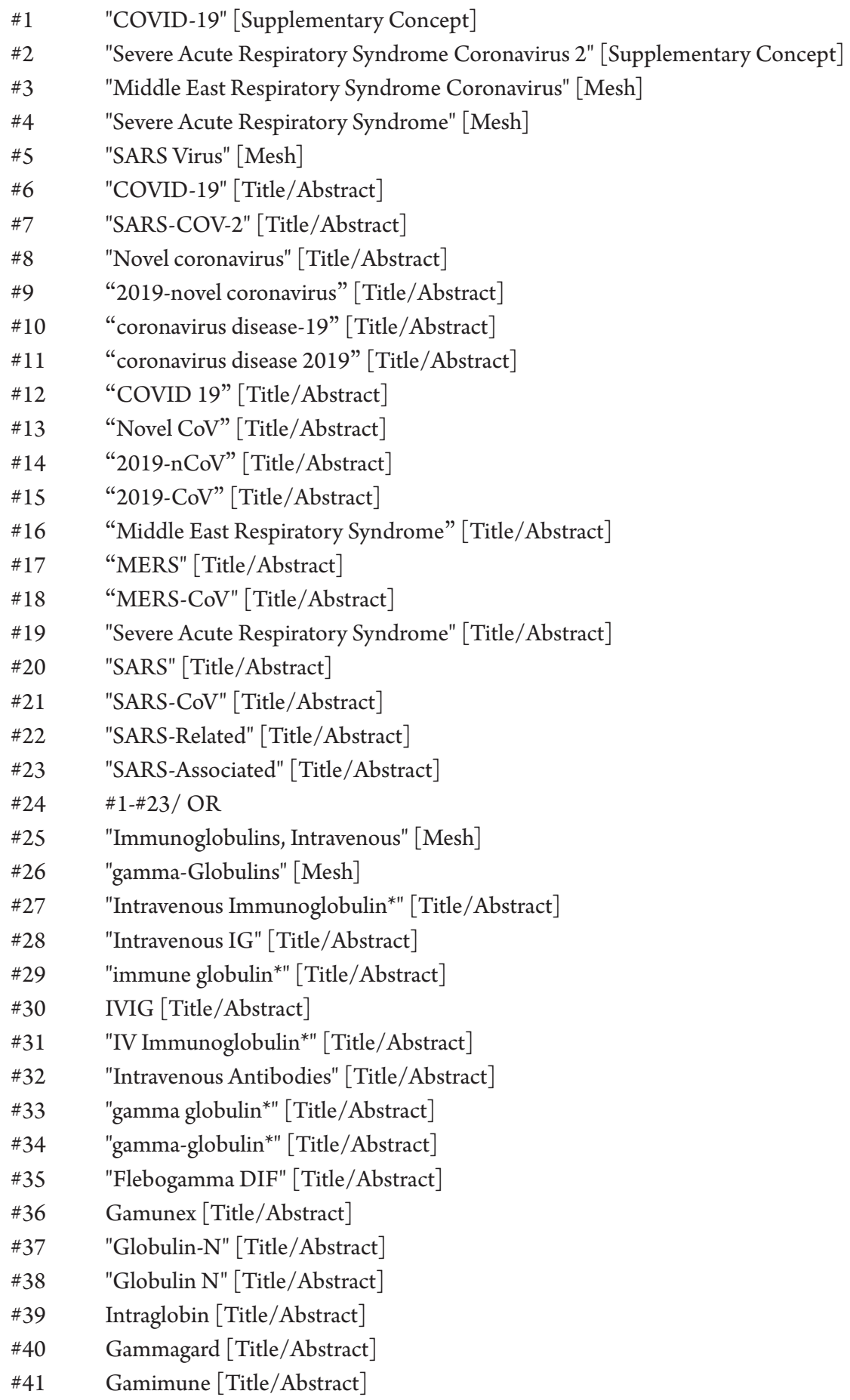




$\begin{array}{ll}\# 42 & \text { Gamimmune [Title/Abstract] } \\ \# 43 & \text { Privigen [Title/Abstract] } \\ \# 44 & \text { Sandoglobulin [Title/Abstract] } \\ \# 45 & \text { Venoglobulin [Title/Abstract] } \\ \# 46 & \text { Iveegam [Title/Abstract] } \\ \# 47 & \text { Endobulin [Title/Abstract] } \\ \# 48 & \text { Gammonativ [Title/Abstract] } \\ \# 49 & \text { \#25-\#48/ OR } \\ \# 50 & \text { \#24 AND \#49 }\end{array}$

\section{Cochrane library}

\#1 MeSH descriptor: [Middle East Respiratory Syndrome Coronavirus] explode all trees

\#2 MeSH descriptor: [Severe Acute Respiratory Syndrome] explode all trees

\#3 MeSH descriptor: [SARS Virus] explode all trees

\#4 "COVID-19":ti,ab,ku=

\#5 "SARS-COV-2":ti,ab,kw

\#6 "Novel coronavirus":ti,ab,kw

\#7 "2019-novel coronavirus":ti,ab,kw

\#8 "Novel CoV":ti,ab,kw

\#9 "2019-nCoV":ti,ab,kw

\#10 "2019-CoV":ti,ab,kw

\#11 "coronavirus disease-19":ti,ab,kw

\#12 "coronavirus disease 2019":ti,ab,kw

\#13 "COVID 19":ti,ab,kw

\#14 "Middle East Respiratory Syndrome":ti,ab,kw

\#15 "MERS":ti,ab,kw

\#16 "MERS-CoV":ti,ab,kw

\#17 "Severe Acute Respiratory Syndrome":ti,ab,kw

\#18 "SARS":ti,ab,kw

\#19 "SARS-CoV":ti,ab,kw

\#20 "SARS-Related":ti,ab,kw

\#21 "SARS-Associated":ti,ab,kw

\#22 \#1-\#21/ OR

\#23 MeSH descriptor: [Immunoglobulins, Intravenous] explode all trees

\#24 MeSH descriptor: [gamma-Globulins] explode all trees

\#25 "Intravenous Immunoglobulin*":ti,ab,kw

\#26 "Intravenous IG":ti,ab,kw

\#27 "immune globulin*":ti,ab,kw

\#28 "IVIG":ti,ab,kw

\#29 "IV Immunoglobulin*":ti,ab,kw

\#30 "Intravenous Antibodies":ti,ab,kw

\#31 "gamma globulin*":ti,ab,kw

\#32 "gamma-globulin*":ti,ab,kw

\#33 "Flebogamma DIF":ti,ab,kw

\#34 "Gamunex":ti,ab,kw

\#35 "Globulin-N":ti,ab,kw

\#36 "Globulin N":ti,ab,kw 


$\begin{array}{ll}\# 37 & \text { "Intraglobin":ti,ab,kw } \\ \text { \#38 } & \text { "Gammagard":ti,ab,kw } \\ \text { \#39 } & \text { "Gamimune":ti,ab,kw } \\ \text { \#40 } & \text { "Gamimmune":ti,ab,kw } \\ \text { \#41 } & \text { "Privigen":ti,ab,kw } \\ \text { \#42 } & \text { "Sandoglobulin":ti,ab,kw } \\ \text { \#43 } & \text { "Venoglobulin":ti,ab,kw } \\ \text { \#44 } & \text { "Iveegam":ti,ab,kw } \\ \text { \#45 } & \text { "Endobulin":ti,ab,kw } \\ \text { \#46 } & \text { "Gammonativ":ti,ab,kw } \\ \text { \#47 } & \text { \#23-\#46/ OR } \\ \text { \#48 } & \text { \#22 AND \#47 }\end{array}$

\section{Web of Science}

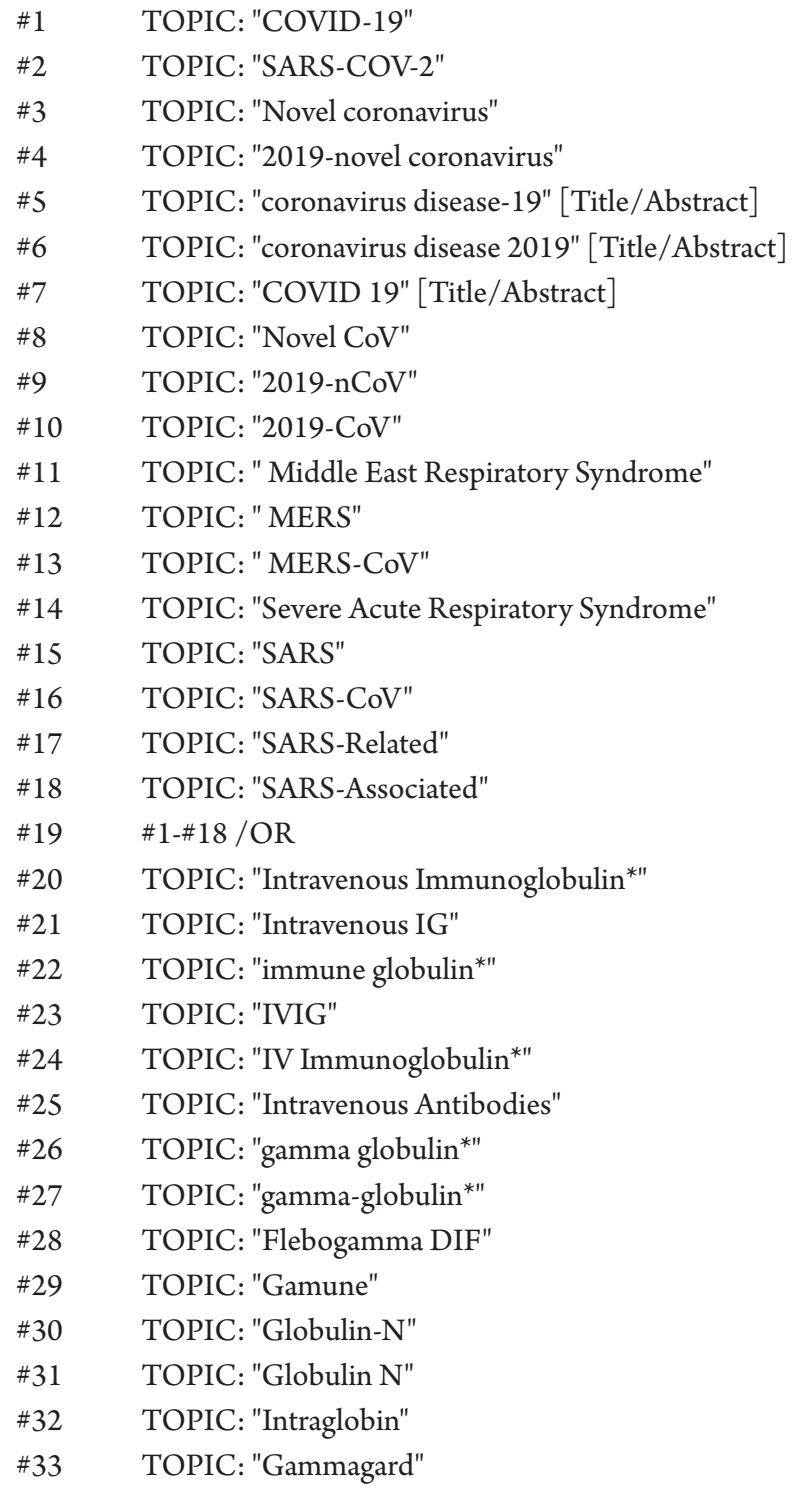




$\begin{array}{ll}\# 34 & \text { TOPIC: "Gamimune" } \\ \# 35 & \text { TOPIC: "Gamimmune" } \\ \# 36 & \text { TOPIC: "Privigen" } \\ \# 37 & \text { TOPIC: "Sandoglobulin" } \\ \# 38 & \text { TOPIC: "Venoglobulin" } \\ \# 39 & \text { TOPIC: "Iveegam" } \\ \# 40 & \text { TOPIC: "Endobulin" } \\ \# 41 & \text { TOPIC: "Gammonativ" } \\ \# 42 & \text { \#20-\#41 /OR } \\ \# 43 & \text { \#19 AND \#42 }\end{array}$

\section{CBM}

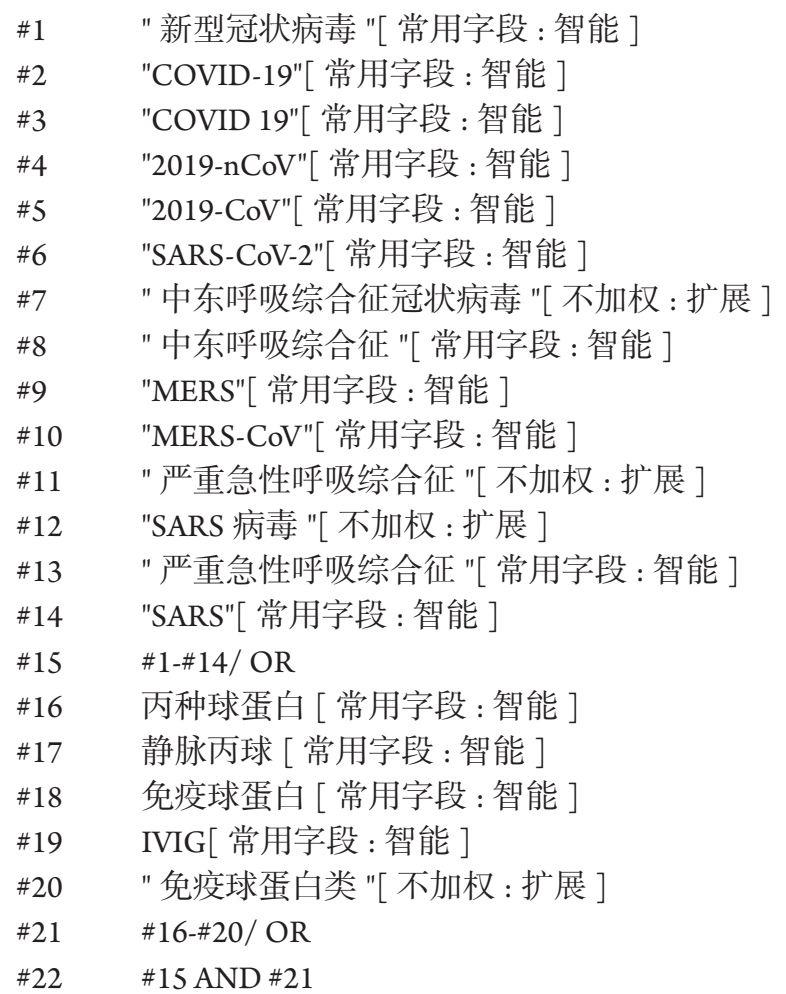

\section{Wangfang}

$\begin{array}{ll}\# 1 & \text { 新型冠状病毒 [ 主题 ] } \\ \# 2 & \text { COVID-19[ 主题 ] } \\ \# 3 & \text { COVID 19[ 主题 ] } \\ \# 4 & \text { 2019-nCoV[ 主题 ] } \\ \# 5 & \text { 2019-CoV[ 主题 ] } \\ \# 6 & \text { SARS-CoV-2[ 主题 ] } \\ \# 7 & \text { 中东呼吸综合征 [ 主题 ] } \\ \# 8 & \text { MERS[ 主题 ] } \\ \text { \#9 } & \text { MERS-CoV[ 主题 ] } \\ \text { \#10 } & \text { 严重急性呼吸综合征 [ 主题 ] }\end{array}$




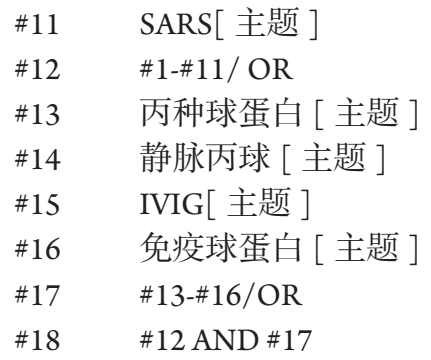

\section{CNKI}

\#1 " 新型冠状病毒 "[ 主题 ]

\#2 "COVID-19"[主题 ]

\#3 "COVID 19"[ 主题 ]

\#4 "2019-nCoV"[ 主题 ]

\#5 "2019-CoV"[ 主题 ]

\#6 "SARS-CoV-2"[ 主题 ]

\#7 " 中东呼吸综合征 "[ 主题 ]

\#8 "MERS"[ 主题 ]

\#9 "MERS-CoV"[ 主题 ]

\#10 " 严重急性呼吸综合征 "[ 主题 ]

\#11 "SARS"[ 主题 ]

\#12 \#1-\#11/ OR

\#13 "丙种球蛋白 "[ 主题 ]

\#14 " 静脉丙球 "[ 主题 ]

\#15 "免疫球蛋白 "[主题 ]

\#16 "IVIG"[ 主题 ]

\#17 \#13-\#16/ OR

\#18 \#12 AND \#17 
Table S1 The characteristics of excluded studies

\begin{tabular}{|c|c|c|c|c|c|c|}
\hline No. & Title & Country & Journal & Year & Study type & Cause \\
\hline 1 & $\begin{array}{l}\text { Five cases of infant hematuria caused by } \\
\text { human immunoglobulin }\end{array}$ & China & $\begin{array}{l}\text { Chinese Journal of Rural } \\
\text { Medicine and Pharmacy }\end{array}$ & 2005 & Case report & $\begin{array}{l}\text { Intramuscular injection } \\
\text { of IVIG }\end{array}$ \\
\hline 2 & SARS: systematic review of treatment effects & US & PLoS Medicine & 2006 & Review & Review \\
\hline 3 & $\begin{array}{l}\text { A hospital outbreak of severe acute respiratory } \\
\text { syndrome in Guangzhou, China }\end{array}$ & China & Chinese medical journal & 2003 & Case series & $\begin{array}{l}\text { Without the outcomes } \\
\text { of efficacy and safety } \\
\text { of IVIG }\end{array}$ \\
\hline 4 & $\begin{array}{l}\text { Comparison of clinical course of patients with } \\
\text { severe acute respiratory syndrome among } \\
\text { the multiple generations of nosocomial }\end{array}$ & China & Chinese Medical Journal & 2004 & Case series & $\begin{array}{l}\text { Without the outcomes } \\
\text { of efficacy and safety } \\
\text { of IVIG }\end{array}$ \\
\hline
\end{tabular}

5 Evaluation of the efficacy and safety of corticosteroid in the treatment of severe SARS in Guangdong province with multi-factor regression analysis

6 The therapeutic effect of high flow nasal cannula oxygen therapy for the first imported case of Middle East respiratory syndrome to China

7 Clinical analysis of pediatric SARS cases in Beijing

8 Clinical analysis of the first patient with imported Middle East respiratory syndrome in China

9 Clinical characteristics and therapy of severe acute respiratory syndrome

10 Multivariable analysis of factors affecting clinical course in patients with SARS

11 Clinical analysis of 136 cases of severe acute respiratory syndrome

12 Evaluation of the efficacy and safety of corticosteroid in the treatment of severe SARS in Guangdong province with multi-factor regression analysis

13 Study of the clinical diagnosis and treatment of the severe acute respiratory syndromes

14 Can immunoglobulin, thymosin, and interferon protect against SARS?

15 The search for therapeutic options for Middle East respiratory syndrome (MERS)

16 Clinical findings, treatment and prognosis in patients with severe acute respiratory syndrome (SARS)

17 Intravenous immunoglobulin $\mathrm{G}$ is remarkably beneficial in chronic immune dysschwannian/ dysneuronal polyneuropathy, diabetes-2 neuropathy, and potentially in severe acute respiratory syndrome

18 Severe acute respiratory syndrome: public health response and clinical practice update for an emerging disease

19 Treatment of severe acute respiratory syndrome

20 Current treatment options and the role of peptides as potential therapeutic components for Middle East respiratory syndrome (MERS): a review

21 Management of hospital-acquired severe acute respiratory syndrome with different disease spectrum

22 Neurological manifestations in severe acute respiratory syndrome

23 Diagnosis and treatment of severe acute respiratory syndrome in children

24 Experience of INF- $\alpha$ for treating severe acute respiratory distress syndrome

25 Study of severe acute respiratory syndrome in Shantou
China Chinese Critical Care Medicine

China Chinese Critical Care Medicine

China Chinese Journal of Pediatrics 2003

China Chinese Critical Care Medicine

China Chinese Famous Doctor Forum

China Journal of Sun Yatsen University (Medical Sciences)

China Chinese Journal of Respiratory and Critical Care Medicine

China Chinese Critical Care Medicine

China Jiangsu Medical Journal

China Hohhot Technology Jounal

Saudi Journal of Infection and

Arabia Public Health

China Journal of the Chinese Medical Association

United Acta Myologica States

2008 Regression Without the outcomes analysis of efficacy and safety of IVIG

2015 Case report Without the outcomes of efficacy and safety of IVIG

Without the outcomes of efficacy and safety of IVIG

2015 Case report Without the outcomes of efficacy and safety of IVIG

2004 Case series Full-text unavailable

2004 Regression Without the outcomes analysis of efficacy and safety of IVIG

2003 Case series Without the outcomes of efficacy and safety of IVIG

2008 Regression Without the outcomes analysis of efficacy and safety of IVIG

2003 Case report Without the outcomes of efficacy and safety of IVIG

2003 Science \& Review Technology

Daily

2016 Editorial Review

2005 Editorial Review

Review Full-text unavailable

United Current Opinion in Pediatrics 2004 Review IVIG not mentioned States

Hong European Journal of Clinical 2005 Kong Microbiology and Infectious Diseases

Saudi Journal of Infection and 2018 Review Review Arabia Public Health

China Journal of the Chinese Medical Association: JCMA

2003 Case report Without the outcomes of efficacy and safety of IVIG

China Acta Neurologica Taiwanica 2005 Review Review

China Journal of Applied Clinical $2003 \quad$ Medical Review Pediatrics

advice

China Journal of Modern Medicine 2004 Case series Without the outcomes \& Health

of IVIG

China Journal of Shantou University Medical College
2003 Case report Without the outcomes of efficacy and safety of IVIG 
Table S2 GRADE evidence profile

\begin{tabular}{|c|c|c|c|c|c|c|c|c|}
\hline $\begin{array}{l}\text { No. of } \\
\text { studies }\end{array}$ & $\begin{array}{c}\text { Sample } \\
\text { size }\end{array}$ & \multicolumn{5}{|c|}{ Certainty assessment } & Effect value (95\% Cl) & Certainty \\
\hline \multicolumn{9}{|c|}{ Serum globulin } \\
\hline $\mathrm{RCT}(31)$ & 44 & Serious $^{1}$ & Not applicable & Serious $^{2}$ & Not serious & None & MD 6.00 (4.75 to 7.25 ) & $\oplus \oplus \bigcirc \bigcirc$ low \\
\hline \multicolumn{9}{|c|}{ Nosocomial infection rate } \\
\hline \multicolumn{9}{|c|}{ The risk of death } \\
\hline RCT (31) & 44 & Serious $^{1}$ & Not applicable & Serious ${ }^{2}$ & Not serious & None & OR 1.70 (0.51 to 0.73$)$ & $\oplus \oplus \bigcirc \bigcirc$ low \\
\hline
\end{tabular}

Explanations: ${ }^{1}$, unclear risk of bias in allocation concealment, random sequence generation and blinding; ${ }^{2}$, using other drugs (such as interferon, hormone, etc.) before intervention. $\mathrm{Cl}$, confidence interval; OR, odds ratio; MD, mean deviation. 